\title{
NOTA SŐBRE A PRESENÇA DO RHODNIUS PROLIXUS STAL, 1859, NO ESTADO DE SÃO PAULO, BRASIL (HEMIPTERA, REDUVIIDAE, TRIATOMINAE). *
}

\author{
Omar Tavares **
}

\begin{abstract}
Através de um lote de ninfas e adultos de Rhodnius, proveniente de Mira Estrêla, Estado de São Paulo, assinalamos pela primeira vez, a presença de Rhodnius prolixus nesse Estado.
\end{abstract}

Entre as espécies de triatomíneos que raramente ocorrem no Brasil, está o Rhodnius prolixus Stal, 1859. As citações mais recentes na literatura acêrca dessa espécie, referem-se sôbre a sua presença nos Estados do Amazonas, Pará, Ceará, Goiás e Minas Gerais (2, 6, 7, 1 e 4).

Corrêa em trabalho apresentado à sessão do Departamento de Higiene e Medicina Tropical, da Associação Paulista de Medicina, assinala a presença de $R$. prolixus em Catanduva, Pindorama e Pitangueiras, Estado de São Paulo. Entretanto, no mesmo ano, êsse autor retifica tal identidade para Rhodnius sp. $(3,6)$.

Posteriormente, com a descrição de Rhodnius neglectus, feita por Lent em 1954, êsse material de Rhodnius sp. foi reconhecido como pertencente a nova entidade taxonômica então estudada. Na mesma ocasião, Lent (5) examinou exemplares de Tapiratiba, Estado de São Paulo, remetidos pelo Dr. Renato Corrêa, identificando-os como $R$. neglectus.

Recentemente, oriundos de Mira Estrêla, Estado de São Paulo, chegou-nos às mãos um lote de ninfas e adultos de Rhod'nius Stal, 1859, capturados em dois ninhos de pássaros, próximos ao teto de uma velha escola. Os exemplares dêsse pequeno lote foram por nós identificados como Rhodnius prolixus Stal, 1859, e Rhodnius neglectus Lent, 1954, através do exame da estrutura genital masculina, cujos detalhes principais estão aqui representados por algumas microfotografias.

A ocorrência de $R$. prolixus no Estado de São Paulo deve ser rara ou tem provàvelmente uma distribuição bastante restrita àquela região.

O recente estudo de Lent \& Jurberg (6) sôbre o gênero Rhodnius contribuiu sem dúvida para um melhor conhecimento do grupo, facilitando, dêsse modo, o reconhecimento mais seguro das identidades das espécies. Nesse estudo, êsses autores apresentam observações sôbre o $R$. prolixus da habitação humana e aquele oriundo de ninho de Mycteria, provenientes da Venezuela, mostrando algumas características bem distintas entre essas duas formas, no aspecto da gonapófise do 9..$^{\circ}$ segmento, ou seja, no material de habitação humana essa gonapófise apresenta poucos pêlos finos, ao passo que nos exemplares de ninho de Mycteria tal gonapófise possui pêlos grossos e numerosos.

Em nosso material de $\boldsymbol{R}$. prolixus de Mira Estrêla, o aspecto da gonapófise do 9.0 segmento é semelhante ao mostrado por Lent \& Jurberg (6) na fig. 204 para o $R$. prolixus encontrado em ninho de Mycteria, embora tais pêlos em nosso material examinado sejam menos numerosos.

\footnotetext{
* Núcleo Central de Pesquisas do Instituto de Endemias Rurais da FIOCRUz, Rlo de Janeiro, Guanabara * Do- Laboratório de Biologia e Contrôle de Insetos. Com auxílio financeiro parcial do Conselho Nacional de Pesquisas.

Recebido para publicação em 20-8-1971
} 

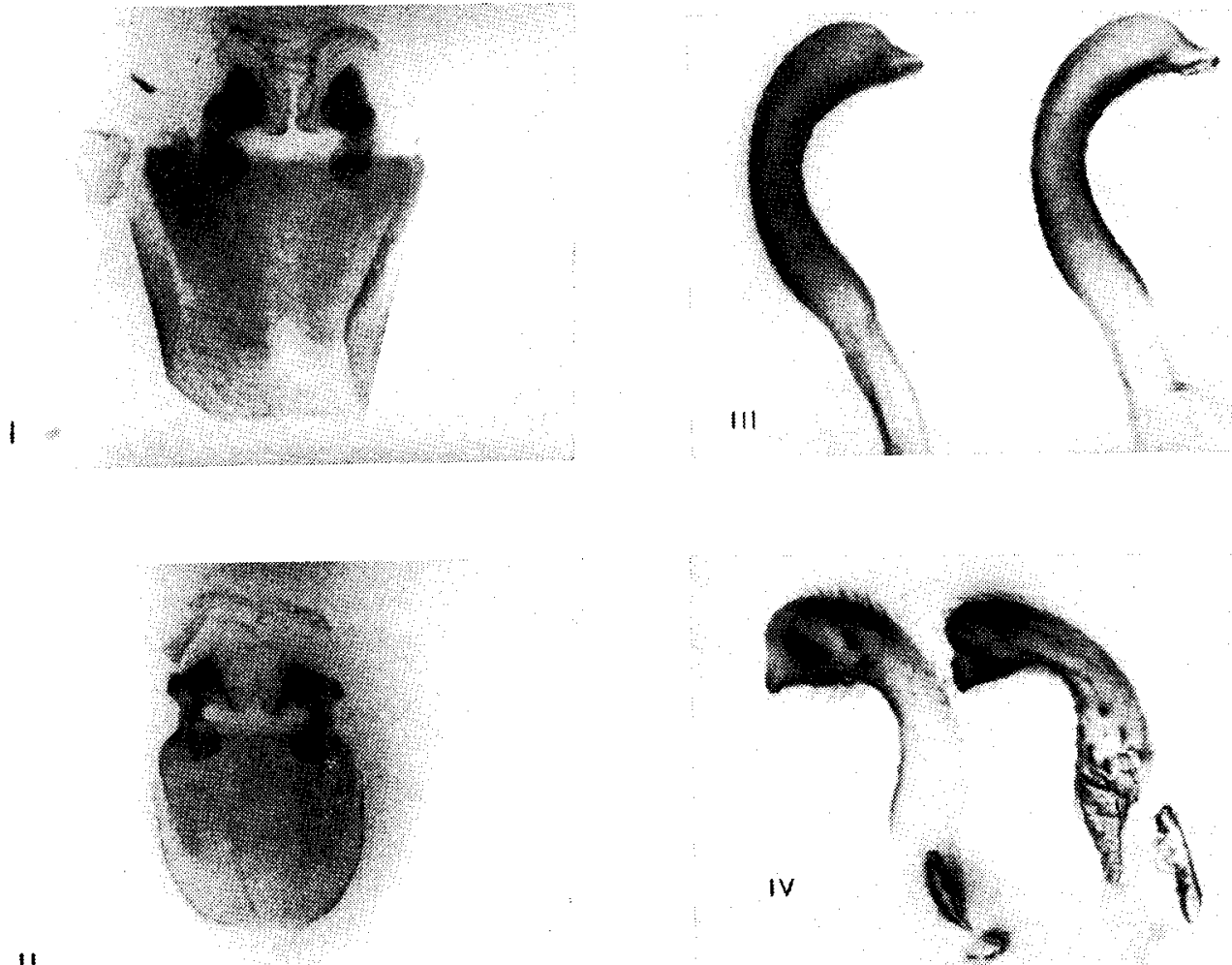

11

Fig. 1 - Falosoma :

Rhodnius prolixus (1-I)

Rhodnius neglectus (1-II)
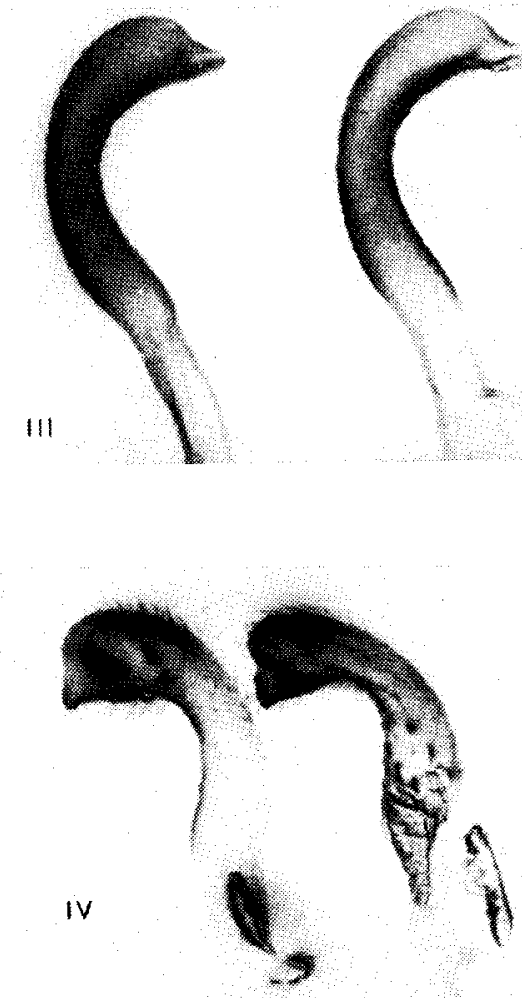

Fig. 2 - Parâmetros:

Rhodnius prolixus (2-III)
Rhodnius neglectus (2-IV) 

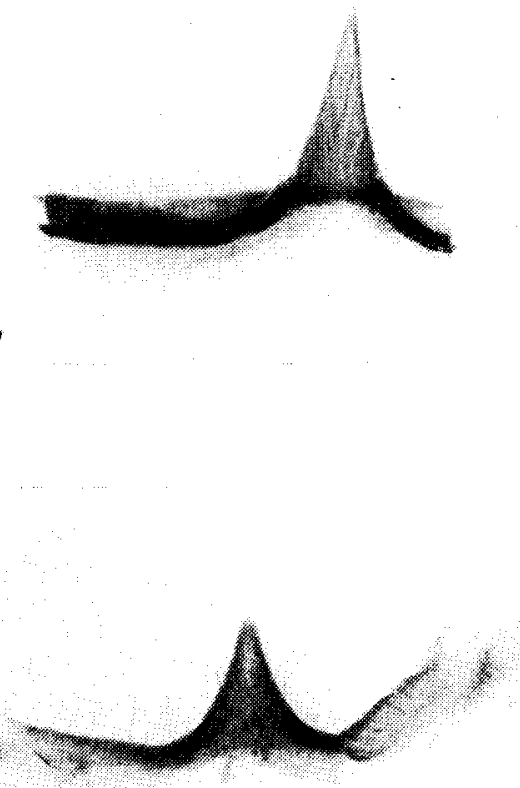

VI

Fig. 3 - Processo mediano do pigóforo: Rhodnius prolixus $(3-\bar{V})$ Rhodnius neglectus (3_VI)

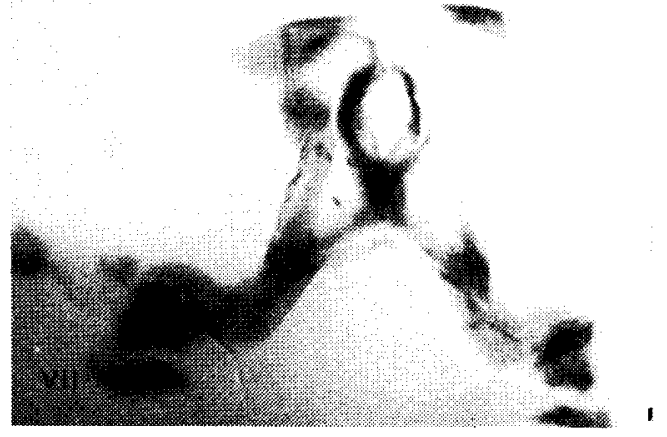

VIII

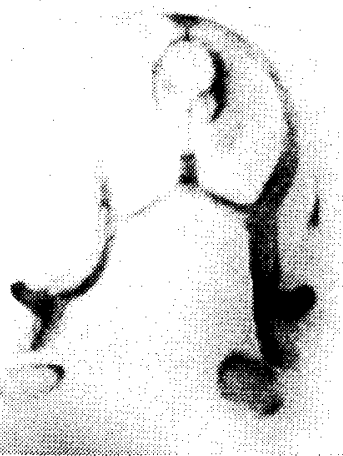

Fig. 4 -Vista parcial do Phallus:

Rhodnius prolixus (4-VII) Rhodnius neglectus (4-VIII) 
Outrossim, notamos também sensíveis diferenças entre o falosoma da forma domiciliar venezuelana mostrada por Lent \& Jurberg (6) na fig. 26 e o encontrado por nós nos exemplares de Mira Estrêla, conforme se pode observar pela fig. 1-I que mostramos aqui. O falosoma de $R$. neglectus está representado na fig. 1-II.

Apresentamos ainda os parâmeros de R. prolixus e $R$. neglectus (figs. 2-III, IV), que diferem entre si pela forma e comprimento, além das cerdas dos parâmeros que na primeira espécie são longas com o ápice afilado, ao contrário da segunda que são mais curtas e possuem o ápice farpelado. Devemos acrescentar que as cerdas da maior parte da região abdominal do $R$. neglectus são truncadas com as extremidades farpeladas, enquanto que em $R$. prolixus, tais cerdas têm o ápice afilado.

O processo mediano do pigóforo das duas espécies em tela é bastante característico, conforme se pode observar pelas figs. $3-\mathrm{V}, 3-\mathrm{VI}$.

Nas figs. 4-VII, VIII, mostramos detalhes parciais do Phallus de $R$. prolixus de Mira Estrêla e o de $R$. neglectus da mesma procedência.

AGRADECIMENTOS. - o autor agradece a Dra. Alina Perlowagora-Szumlewicz, Chefe do Laboratório de Biologia e Contrôle de Insetos do Núcleo Central de Pesquisas do INERu, pelas valiosas sugestões apresentadas durante a elaboração dêste trabalho.

\section{SUMMARY}

Published recora's dealing with the distribution of Rhodnius prolixus Stal, 1859 in Brazil demonstrated the absence of this species in the State of São Paulo. Insects of the genus Rhodnius Stal, 1859 collected by Corrêa in the State of Sáo Paulo and considered by the author previously as R. prolixus and thereafter as Rhodnius sp. have been shown by Lent to be R. neglectus.

Morphological characters used to distinguish these two species by Lent \& Jurberg helpeld to recognize the presence of Rhodnius prolixus in a group of R. neglectus collected by us in Mira Estrêla in the State of São Paulo.

Large colonies of these two species have been established in the Laboratory of Insect Biology and Vector Control.

\section{BIBLIOGRAFIA}

1. Carvalho, A. G. \& Verano, $O$. T. - Epidemiologia e Profilaxia da Doença de Chagas em Goiás. Rev. Goiana Med., 2: 241-278, 1965.

2. CORREA, R. R. - Informe sôbre a Doença de Chagas no Brasil e em especial no Estado de São Paulo. Rev. Brasil. Malariol. D. Trop. 20 (1/2): 39-339, figs., 1968 .

3. CORREA, R. R. \& LIMA, A. R. Nota sôbre o gênero Rhodnius Stal, 1859 no Estado de São Paulo, Brasil. Arq. Hig. S. Publ., São Paulo, 18 (57): 267-280, figs. 1-19, mapa, 1953.

4. LENT, H. - O gênero Rhodnius Stal, 1859 (Hemiptera, Reáuviidae). Rev.
Brasil. Biol. 8 (3) : 297-339, figs. 1-47, 1948.

5. LENT, H. - Comentários sôbre o gênero Rhodnius Stal, 1859, com descrição de uma nova espécie do Brasil (Hemiptera, Reduviidae). Rev. Brasil. Biol., 14 (3): 237-247, figs. 120, 1954 .

6. LENT, H. \& JURBERG, J. - O gênero "Rhodnius" Stal, 1859, com um estudo sôbre a genitália das espécies (Hemiptera, Reduviiaiae, Triatominae). Rev. Brasil. Biol. 29 (4): 487560, figs. 1-219, 1 estampa, 1969.

7. LUCENA, D. T. - Ecologia dos triatomíneos do Brasil. Rev. Brasil. Malariol. D. Trop., (11): 577-635, 1959. 